\title{
CONTRIBUIÇÃO AO ESTUDO DO "VERMELHÃO» DO ALGODOEIRO (Gossipium herbaceum)
}

2.0 CONGRESSO PANAMERICANO DE AGRONOMIA E. S. A. "LUIZ DE QUEIROZ", U. S. P.

Piracicaba, Março-abril de 1954

T. COURY, E. MALAVOLTA, G.RANZANI e M. O. C. DO BRASIL SOBRINHO

Seção Técnica de Química Agrícola, E. S. A. "Luiz de Queiroz", U. S. P. Piracicaba, S. Paulo, Brasil

DEDICATÓRIA - Êste trabalho é dedicado à memória do Prof. R. AVERNA-SACCÁ

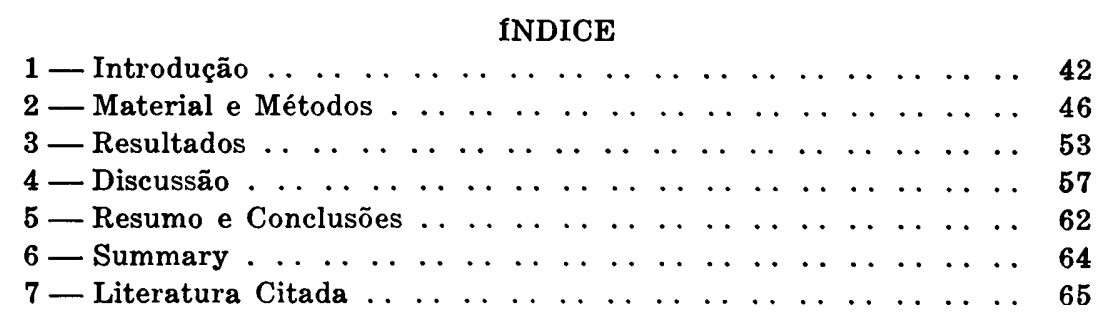




\section{1 - INTRODUÇÃO}

\subsection{O Potássio e as plantas.}

Ainda que, de vez em quando, se atribua ao potássio importantes papéis no metabolismo vegetal, o mecanismo da sua função em processos biológicos não foi até agora elucidado (MULDER, 1950 , p. 10). O potássio permanece como um elemento intrigante para o fisiologista vegetal. COOIL (148) em experimentos com guayule verificou um teor mais alto de ácido cítrico em plantas alimentadas com grandes quantidades de potássio do que naquelas com menos potássio. Uma relação direta foi encontrada entre potássio fornecido e ácido málico na planta. COOIL e SLATTERY (1948) notaram um teor maior de carbohidratos, particularmente açúcares redutores como também de compostos nitrogenados (nitrogênio amínico e amídico) nas folhas de guayule deficiente em potássio. Resultados semelhantes foram obtidos por MULDER (1949) em pastagens.

Provas obtidas por STOUT et al. (1947) em estudos com isótopos radiativos serviram de ponto de partida para os trabalhos de OLSEN (1948 a, b) o qual verificou que, ao contrário de idéias aceitas por muito tempo, até $30 \%$ do potássio total das folhas está presente em forma combinada - e não como o iônio - como um composto de adsorção provàvelmente com proteinas. Recentemente HEWITT (1951, p. 25) expressou a opinião de que "potassium, and to some extent calcium in complementary fashion, maintain cell organisation, hidration and permeability and hence directly or indiretly influence many enzyme systems, e. g., the condensation or hydrolysis systems inferred by COOIL and SLATTERY (1948)". Hewitt se refere à descoberta de COOIL e SLATTERY de que a relação nitrogênio orgânico solúvel-nitrogênio proteico é mais elevada $\epsilon \mathrm{m}$ plantas deficentes em $\mathrm{K}$, de acôrdo, aliás, com uma antiga sugestão de que o potássio tem papel na formação de proteinas a partir de compostos solúveis.

Um importante efeito do potássio é a sua capacidade para garantir formação normal de clorofila quando o ferro é limitante (WALLACE and HEWITT, 1946; JONES and HEWITT, (1950). Aparentemente a utilização de quantidades limitadas de $\mathrm{Fe}$ é mais eficiente quando a proporção de potássio é adequada. Um efeito recíproco, em que altos níveis de ferro causam retenção temporária do potássio nas folhas mais velhas impedindo a translocação normal para as partes jovens, em condições de deficiência já foi relatado (JONES and HEWITT, 
1950). A possível relação entre êsse feito e a natureza do $K$ adsorvido apresenta interêsse.

O metabolismo dos carbohidratos é perturbado quando o fornecimento de $\mathrm{K}$ é inadequado. Há evidência de que a fotosíntese é reduzida e que a respiração aumenta quando há severa deficiência de potássio. Os efeitos de baixos níveis de $\mathrm{K}$ são aparentes primeiro no metabolismo desorganisado do nitrogênio, o que, por causa da impossibilidade da síntese de proteinas leva a um acréscimo inicial na quantidade de carbohidratos. Continuando a deficiência de potássio há uma diminuição na quantidade de carbohidratos provàvelmente devido a uma limitação na fotosíntese e acréscimo na respiração.

O potássio é altamente móvel na planta. A redistribuição interna dêsse elemento ocorre fácil e mais ou menos continuamente durante o ciclo vital. Os tecidos em crescimento mais ativo, aparentemente têm a maior capacidade para acumulação de $\mathrm{K}$ em contraste com as células menos ativas fisiològicamente (ARNON and HOAGLAND, 1943). O potássio é usualmente o catiônio monovalente mais abundante nas células vegetais. Ainda que não possa ser substituido inteiramente por nenhum outro elemento, os sintomas de deficiência aparecem mais cedo e são mais severos em cevada na ausência de sódio, do que quando êsses catiônios estão presentes na solução nutritiva (MULLISON and MULLISON, 1942). E' provável, portanto, que durante os primeiros estágios de crescimento, o potássio pode ser substituido parcialmente por sódio, pelo menos em algumas espécies de plantas. Como respeito a êsse problema, LEHR (1949-50) estudou o efeito do NaNO3 comparado com Ca (NO3) 2 no crescimento e absorção de cationnics em espinafre cultivado em solo e em misturas artificiais de solo com 3 niveis de potássio. Colheitas muito maiores foram obtidas com as plantas tratadas com sódio, especialmente quando o nível de potássio era baixo, de modo que Lehr concluiu que o sódio pode substituir o potássio em grande extensão.

\subsection{O magnésio $e$ as plantas.}

O magnésio é um dos elementos essenciais para o crescimento das plantas. Entretanto as suas funções específicas e os mecanismos pelos quais tais funções são desempenhadas ainda não estão totalmente estabelecidas.

O $\mathrm{Mg}$ representa 2,7 por cento da molécula de clorofila da qual é um constituinte indispensável (WILLSTATTER und STOLL, 1913). Por essa razão o sintoma característico da carência de $\mathrm{Mg}$ é inicialmente uma cloróse internerval que começa 
nas bordas e gradualmente caminha para o centro à medida que se acentua a deficiência (ZIMMERMAN, 1947). RABINOWITCH (1945) observa que a falta de magnésio afeta desfavoràvelmente a formação de clcrofila e, de modo indireto, a fotosíntese. MAMELI (1912) estudando o efeito do Mg no desenvolvimento da clorofila em algas, milho, girasol e trigo notou que a quantidade de matéria verde extraida estava em direta proporção com o teor de $\mathrm{Mg}$ na solução nutritiva. Como apenas uma pequena porção do Mg foliar está na clorofila (JAVILLIER et GOUDSHAUX, 1940), foi sugerida a seguinte explicação : para impedir o desdobramento da clorofila, a quantidade total de $\mathrm{Mg}$ na folha deve ser várias vêzes maior do que a presente na clorofila.

Atuando como um vetor para o aniônio fcsfato, atribue-se ao Mg um papel na formação de fosfolipídecs e na síntese das nucleo-proteinas (LOW, 1903). Como apôio dessa teoria cita-se que o $\mathrm{Mg}$ é abundante nos jovens tecidos meristemáticos, na semente e no fruto. TRUOG et al. (1947) verificaram em ervilha que houve um consistente aumento no $\mathrm{P}$ das sementes como resultado da aplicação de doses crescentes de $\mathrm{Mg}$; ainda mais, a ação das doses extras de $\mathrm{Mg}$ foi muito mais acentuada do que aquela de quantidades adicionais do próprio $\mathrm{P}$.

Uma ilustração de que o $\mathrm{Mg}$ se concentra nas sementes bem como da sua translocação é dada por CIFERRI (sem data) mencionando que o feijoeiro é capaz de executar todo o seu ciclo de vida graças à reserva magnesiana da semente. Com respeito à formação de óleos e proteinas: LOW (1903) verificou uma porcentagem unusualmente elevada de Mg em sementes oleag nosas quando comparadas com amiláceas, a razão sendo de 5:2.

A literatura sôbre as relações solc-planta contém muitos exemplos dos efeitos depressivos das altas concentrações de $\mathrm{Ca}$ e $\mathrm{K}$, particularmente do último, na absorção do $\mathrm{Mg}$ pelo vegetal. Assim WALSH e CLARKE (1945) notaram que a relação $\mathrm{K}: \mathrm{Mg}$ no solo determinava o gráu de absorção do último pelo tomateiro. Se a relação fosse suficientemente alta, havia o aparecimento de clorose mesmo quando o meio nutritivo tenha uma quantidade elevada de $\mathrm{Mg}$ assimilável. WALSH e O'DONOHOE (1945) verificaram que quando batata, fumo, beterraba, etc., mostravam sintomas de carência de $\mathrm{Mg}$ havia uma quantidade anormalmente alta de $\mathrm{K}$ trocável no solo. De acôrdo com BARNES (1943), batatas cultivadas em solo ácido tiraram muito pouco beneficio da aplicação de $K$, a menos que o fornecimento de $\mathrm{Mg}$ fosse adequado (o grifo é nosso). 
Uma importante função genérica do $\mathrm{Mg}$ nas plantas é a ativação de enzimas contendo grupos sulfidrilo ( $\mathrm{SH}-$ ) especialmente daquelas implicadas no metabolismo do fósforo e, através dês'e, na respiração (DIXON, 1949).

Antes de terminar : a primeira observação de sintomas de carência de $\mathrm{Mg}$ em condiçües de campo registrada na literatura foi feita pelo falecido AVILRNA-SACCA (1912) quando professor de Botânica na "Luiz de Queiroz".

\subsection{O problema.}

Durante os anos agrícolas de 1948, 1949 e 1951 ocorreu nas culturas de algodoeiro de: várias regiões do estado de $\mathrm{S}$. Paulo um avermelhamento (vermelho púrpura) das folhas muito acentuado. A incidência teve luggar principalmente em solos de baixa fertilidade ou não adubaclos convenientemente, aparecendo por ocasião da abertura das maçãs; as fôlhas de situação inferior eram atingidas em primeiro lugar e caíam prematuramente; além disso muitas das maçãs não se abriam e caíam. Houve, como consequência, um decréscimo de produção nas zonas afetadas.

As opiniões dos técnicos tentando explicar a anomalia eram as mais diversas possiveis; para alguns, como SAUER (1950) o avermelhamento das folhas do algodoeiro seria uma consequência do ataque do pulgão; usando-se inseticidas no combate a essa praga, houve menor ocorrência da doença que não chegou a afetar sensivelmente a produção; a explicação proposta foi textualmente, a seguinte: "As lesões causadas pelos insetos nas folhas impedem de maneira parcial a transferência (translocação) dos produtos da assimiliação para os caules e as raízes. E' o que sucede principalmente com os açúcares, que se acumulam nas folhas, particularmente nas partes superiores, e não descem para a parte inferior da planta. Como resultado as folhas se avermelham e prejudicam o desenvolvimento do algodoeiro, podendo afetar parcial ou totalmente a produtividade". Para ABRAHÃO et al. (1952) a causa primária da doença seria uma falta de potássio assimilável no solo na ocasião de formação e maturação das maçãs; a "fome de potássio" provocaria então um desequilíbrio fisiológico entre a folhagem e a frutificação; esse autores verificaram ainda haver uma diferença na sensibilidade de diferentes variedades ao "vermelhão"; assim a variedade "Campinas" é mais sujeita que a "Express" em virtude de a folhagem ser muito pouco desenvolvida em relação ao número de maçãs. A opinião de que o potássio era o agente causal foi aceita também por BEMELMANS (1952) e HACKEMANN (1952). 
Os membros da Secção Técnica "Química Agrícola" da E. S. A. "Luiz de Queiroz" tiveram oportunidade de percorrer várias culturas, em solos distintos, as quais mostraram o "vermelhão". Material e amostras de terra foram colhidas, trazidas para o laboratório e analisadas. Comparando os sintomas mostrados pelas plantas com a literatura à disposição foi constatada uma grande semelhança entre o "vermelhão e os sinais de carência de magnésio. Assim MC MURTREY (1948), por ex., dá literalmente a seguinte descrição: as folhas mais velhas primeiramente mostram uma clorose atenuada entre as veias, seguida pelo aparecimento duma coloração vermelho púrpura ficando as veias verdes; há queda prematura das folhas. Tal sintomatologia é bastante diferente daquela dada para o potássio por ECKSTEIN, BRUNO e TURRENTINE (1937): à medida que a carência progride, aumenta a incidência da ferrugem (cotton rust); esta tem uma cor pardacenta fácil de distinguir do vermelho-púrpura que ocorre quando há falta de Mg. Deve-se mencionar ainda a coloração vermelho-alaranjada que sempre aparece nas fôlhas do algodoeiro no fim do ciclo. Segundo COOPER et al. (1934) a ferrugem do algodoeiro é devida largamente à deficiência de potássio, sendo muito mais grave em anos de sêca.

\section{2 - MATERIAL E MÉTODOS}

\subsection{Ensaios em vasos.}

2.1.1. Ensaios com terra da região afetada.

2.1.1.A. Terra sem variação no fator água.

Foi coletada terra na Faz. Sta. Gertrudes, município de Araras, onde a ocorrência do "vermelhão" fôra muito acentuada. A análise feita pelos métodos da Seç̧ão de Agrogeologia do Instituto Agronômico do Estado de S. Paulo (Campinas) (PAIVA NETTO et al., 1950) revelou o seguinte :




As amostras de terra, uniformizadas e peneiradas (peneira de $2 \mathrm{~mm}$ ) foram postas em vasos de Mitscherlich cada um dos quais recebeu $10 \mathrm{Kg}$. Os tratamentos foram os seguintes :

\section{QUADRO 1}

Tratamento

Vasos

\section{Adubação}

1
2
3
4
5

1, 2, 3, 4 Testemunha

5, 6, 7, 8 N $\mathrm{N}-\mathrm{P}-\mathrm{Ca}$ sem $\mathrm{K}$ e $\mathrm{Mg}$

$9, \quad 10,11,12 \mathrm{~N}-\mathrm{P}-\mathrm{K}-\mathrm{Ca}$ sem $\mathrm{Mg}$

$13,14,15,16 \mathrm{~N}-\mathrm{P}-\mathrm{Ca}-\mathrm{Mg}$ sem $\mathrm{K}$

17, $18,19,20 \mathrm{~N}-\mathrm{P}-\mathrm{K}-\mathrm{Ca}-\mathrm{Mg}$ completa

Os adubos foram empregados nas seguintes proporções :

$\begin{array}{ll}\text { Salitre do Chile } & -10 \mathrm{~g} \text { por vaso } \\ \text { Superfosfato simples } & =40 \mathrm{~g} \text { por vaso } \\ \text { Calcário } & =10 \mathrm{~g} \text { por vaso } \\ \mathrm{KCl} & =10 \mathrm{~g} \text { por vaso } \\ \mathrm{MgSO} 4 & -5 \mathrm{~g} \text { por vaso }\end{array}$

Cada vaso recebeu 8 sementes da variedade "Express" (18-10-49); no desbaste (18-11-49) deixaram-se 2 pés por vaso. A irrigação foi feita do modo preconizado por MITSCHERLICH (1930).

No decorrer do ensaio foram feitas várias pulverizações contra o pulgão.

As seguintes medições foram feitas: altura das plantas, contagem dos capulhos e produção (fibras).

\subsubsection{B. Terra com variação no fator água.}

O presente ensaio foi conduzido com terra igual à usada em 2.1.1.A. Empregou-se vasos de barro vidrado e esmaltado com um coletor do mesmo material. Cada vaso recebeu 10 quilos de terra; igualou-se o pêso dos vasos graças a pedaços de telha e areia lavada. O poder de embebição da terra foi $37,8 \%$. Os tratamentos foram os do Quadro 2 :

A umidade foi mantida constante mediante reposição diária da água evaporada ou transpirada pelas plantas; para isso foram colocados quatro tubos de vidro que se abriam a alturas variáveis do cone de terra do vaso; assim se conseguia uma distribuição mais ou menos uniforme da água evitando - principalmente nos casos em que a água era pouca -- que só se umidecessem as camadas superiores. 


\section{QUADRO 2}

Tratamento

Vasos

Adubação

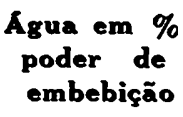

25

50

75

75

50

75

25

50

75

25

50

75

25

50

75

Todos os ensaios em vasos foram conduzidos em casa de vegetação.

\subsubsection{Ensaio em areia lavada.}

Vasos de barro esmaltado e vidrado foram cheios com 8 quilos de areia lavada de acôrdo com PFEIFFER (1918). Sob cada vaso havia o coletor do mesmo material. Dez tratamentos cum quatro repetições foram usados neste ensaio como se segue:

\section{QUADRO 3}

\section{Vasos}

$1,2,3,4$

$5,6,7,8$

$9,10,11,12$

$13,14,15,16$

$17,18,19,20$

$21,22,23,24$

$25,26,27,28$

$29,30,31,32$

$33,34,35,36$

$37,38,39,40$
Tratamento

Solução nutritiva completa

Solução nutritiva sem potássio

Solução nutritiva sem magnésio

Solução nutritiva sem potássio e magnésio

Solução nutritiva com pouco potássio

Solução nutritiva com pouco magnésio

Solução nutr. com pouco potássio e magnésio

Sem potássio 60 dias após germinação

Sem magnésio 60 dias após germinação

Sem potássio e magnésio 60 dias após germinação

As soluções nutritivas eram renovadas semanalmente depois de lavagem da areia com água destilada. Usou-se sempre as soluções indicadas por HOAGLAND e ARNON (1950). No 
caso das soluções com pouco $\mathrm{K}$ ou $\mathrm{Mg}$ ou ambos, a dose desses elementos empregada foi um vigésimo da habitual. No caso dos três últimos tratamentos (vasos 29 a 40) as plantas foram cultivadas durante 60 dias em caixas de areia com solução completa e depois transferidas para os vasos. Cada vaso recebia 1 litro de solução. A seguir vêm as diversas soluções empregadas no ensaio :

Solução completa

\section{Sais}

$\mathrm{KH} 2 \mathrm{PO} 4 \mathrm{M}$

$\mathrm{KNO} 3 \mathrm{M}$

$\mathrm{Ca}(\mathrm{NO} 3) 2 \mathrm{M}$

$\mathrm{MgSO} 4 \mathrm{M}$

$\mathrm{Ca}$ (NO3) $2 \mathrm{M}$

$\mathrm{MgSO} 4 \mathrm{M}$

$\mathrm{Ca}$ (H2PO4) 2 0,05 M

$\mathrm{Ca}$ (NO3) $2 \mathrm{M}$

KNO3 M

KH2PO4 M

$\mathrm{K} 2 \mathrm{SO} 4$ 0,5 M

$\mathrm{Na2HPO4}$

$\mathrm{Ca}$ (NO3) 2 1,5 M

$\mathrm{Na} 2 \mathrm{SO} 4 \mathrm{M}$

$\mathrm{KCl} 0,05 \mathrm{M}$

$\mathrm{Na} 2 \mathrm{HPO} 4 \mathrm{M}$

$\mathrm{Ca}$ (NO3) 2 1,5 M

MgSO4 M

KH2PO4 M

$\mathrm{KNO} 3 \mathrm{M}$

$\mathrm{Ca}$ (NO3) $2 \mathrm{M}$

MgSO4 0,05 M

$\mathrm{KCl} 0,05 \mathrm{M}$

$\mathrm{Na} 2 \mathrm{HPO} 4 \mathrm{M}$

$\mathrm{Ca}$ (NO3) 2 1,5 M

MgSO4 0,05 M ce. por litro de solução

$\mathbf{1}$

5

2

Solução sem K

5

10

Solução sem $\mathrm{Mg}$

4

6

1

Solução sem $\mathrm{K}$ e $\mathrm{Mg}$

1

6

2

Solução com pouco $\mathrm{K}$

7
1
6
2

Solução com pouco $\mathrm{Mg}$

1
6
4
2

Solução com pouco $\mathrm{K}$ e $\mathrm{Mg}$ 
Além disso, em todos os vasos foram adicionados ferro (1 cc por litro de solu. nutr. duma solução de citrato a $0,5 \%$ ) e micronutrientes do modo seguinte:

$\begin{array}{lc}\text { Droga } & \begin{array}{c}\text { Gramas em 1 litro } \\ \text { de água }\end{array} \\ \text { H3BO3 } & 2,86 \\ \text { MnCl2 } & 1,81 \\ \text { ZnSO4 } & 0,22 \\ \text { CuSO4 } & 0,08 \\ \text { H2MoO4 } & 0,02\end{array}$

A solução de micronutrientes também foi adicionada na proporção de 1 cc por litro de solução nutritiva.

2.2. Ensaio de campo.

O ensaio foi realizado no campo experimental da Secção Técnica de Química Agrícola, da Escola Superior de Agricultura "Luiz de Queiroz", Universidade de São Paulo, Piracicaba, Estado de São Paulo. Trata-se de um solo arenoso, cujas características são as seguintes :

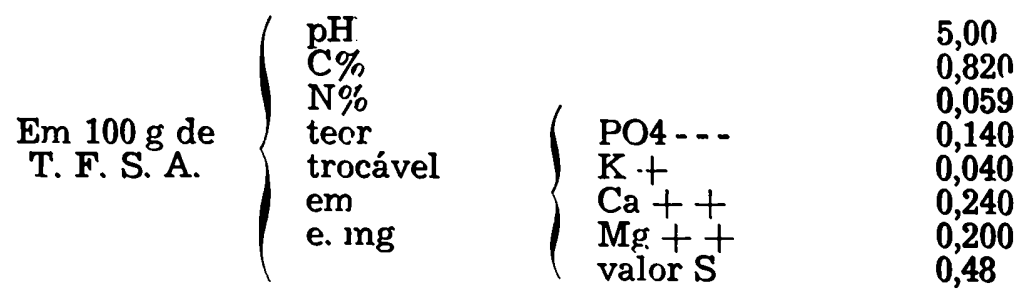

Os resultados acima representam a média de 5 determinações com variações mínimas. Como as diferentes variedades do algodão se comportam diferentemente em relação ao "vermelhão", foram ensaiadas três variedades mais comuns e recomendadas pela Secretaria da Agricultura do Estado, nos anos recentes. São elas :

$$
\begin{aligned}
& \text { IA }-7387-24940-\text { Texas. } \\
& \text { IA }-7177-028-16824-\text { Express. } \\
& \text { IA }-817 \text { - Instituto Agronômico. }
\end{aligned}
$$

Os tratamentos foram os seguintes:

1 - N P Ca Mg (forma solúvel) - sem Potássio

2 - N P K Ca - sem magnésio

3 - N P K Ca Mg - (forma solúvel) - completa

4 - N P K Ca Mg (forma pouco solúvel) - completa 
Um dos tratamentos deixou de receber o potássio com a finalidade de ficar evidenciado o papel do magnésio. Este, por sua vez, foi adicionado nas formas solúvel e pouco solúvel em dose 2,5 vêzes maior na última; a primeira forma foi constituida pelo sulfato de magnésio e a segunda pelo calcário dolomítico. Doses em cálcio, correspondentes à da dolomita, foram adicionadas aos outros tratamentos, como cal extinta, isenta de magnésio (ver Quadro 4)

\begin{tabular}{|c|c|c|c|c|c|}
\hline \multicolumn{6}{|c|}{ QUADRO 4} \\
\hline Adubos & $\%$ & $\begin{array}{l}\text { elem. } \\
\text { ort. }\end{array}$ & $\begin{array}{c}\text { Dose p/ ha. } \\
\text { Kg. }\end{array}$ & $\begin{array}{l}\text { Dose por } \\
\text { canteiro g. }\end{array}$ & $\begin{array}{l}\text { Dose por } \\
\text { sulco } 8 \text {. }\end{array}$ \\
\hline Salitre do Chile & $15 \%$ & $\mathrm{~N}$ & 167 & 400 & 50 (F'und.) \\
\hline $\begin{array}{l}\text { Torta Algodão } \\
\text { Superfosfato } \\
\text { Fertifos } \\
\text { Sulf. Potássin } \\
\text { Sulf. Magnésio } \\
\text { Dolomita }\end{array}$ & $\begin{array}{l}5 \% \\
20 \% \\
40 \% \\
50 \% \\
15 \% \\
27 \% \\
18.8 \%\end{array}$ & $\begin{array}{l}\mathrm{N} \\
\mathrm{P} 2 \mathrm{O} 5 \\
\mathrm{P} 2 \mathrm{O} 5 \\
\mathrm{~K} 20 \\
\mathrm{MgO} \\
\mathrm{CaO} \\
\mathrm{MgO}\end{array}$ & $\begin{array}{l}500 \\
334 \\
334 \\
167 \\
334 \\
665\end{array}$ & $\begin{array}{r}1200 \\
800 \\
800 \\
400 \\
800 \\
1096\end{array}$ & $\begin{array}{l}300 \\
200 \\
200 \\
100 \\
200 \\
400\end{array}$ \\
\hline Cal extinta & $36,5 \%$ & & $49 n$ & $11 \% 6$ & 295 \\
\hline
\end{tabular}
plantío.

O salitre f $\supset$ i aplicado metade em cobertura 50 dias após o

O delineamento experimental foi o de blocos ao acaso, (A, B, C, D), com 4 repetições; tinhamos, portanto, 16 canteiros, com a distribuição segundo o esquema do Quadro 5.

\section{QUADRO 5}

Esquema experimental

\begin{tabular}{|c|c|c|c|c|c|}
\hline 1 & C & 3 & 1 & D & 3 \\
\hline 2 & & 4 & 4 & & 2 \\
\hline 1 & A & 2 & 3 & B & 4 \\
\hline 4 & & 3 & 2 & & 1 \\
\hline
\end{tabular}


Os canteiros tiveram $4 \times 6 \mathrm{~m}$, com 4 linhas guardando o espaçamento de $1 \mathrm{~m}$. A distância entre as plantas foi de $0,5 \mathrm{~m}$, tendo, pois, cada linha, 12 covas, sendo conservadas por ocasião do desbaste, duas plantas para cada uma destas últimas. Tivemos assim, em cada canteiro, 48 covas. A semeadura foi feita na proporção de 8-10 sementes por cova. Entre os diversos canteiros foi guardada uma linha de proteção ou bordadura.

\subsection{Análises químicas.}

2.3.1. Amostragem. A. O material de uma das culturas visitadas no Município de Piracicaba foi colhido em diversos pontos, uniformizado e tiradas amostras médias representativas; as folhas foram classificadas de acôrdo com o gráu de incidência da moléstia em: verdes, pintadas, verde-avermelhadas e vermelhas; além disso separou-se os limbos dos pecíolos analisando-se isoladamente.

B. No caso do ensaio 2.1.1.B. tirou-se folhas de cada vaso em tôda a altura das plantas.

C. Do ensaio de campo (2.2.) colheu-se folhas dos canteiros que não haviam recebido $K$, nos quais os sintomas de "cotton rust" e não de "vermelhão" eram bem típicos; colheu-se também, para comparação, material dos canteiros tratados com $\mathrm{K}$. Aquí também, foi feita a separação entre limbos e pecíolos.

2.3.2. Preparo das amostras. A secagem foi feita em estufa a $80^{\circ} \mathrm{C}$; depois as amostras foram trituradas em moinho de facas até passar por peneira de $0,5 \mathrm{~mm}$, colocadas em vidros de rolha esmerilhada e guardadas para análise.

\subsubsection{Incineração. Feita em forno elétrico a $550^{\circ} \mathrm{C}$.}

2.3.4. Métodos analíticos. O material citado em 2.3.1.A. foi analisado segundo os métodos dados a seguir (2.3.4.A. e 2.3.4.B.) enquanto as amostras dos ensaios 2.1.1.B e 2.2. foram analisadas de acôrdo com 2.3.4.C. e 2.3.4.D.

A.Potássio. Determinado gravimètricamente como perclorato no extrato clorídrico das cinzas (A.O.A.C., 1948)

B. Magnésio. Determinado gravimètricamente como pirofosfato no extrato clorídrico das cinzas (WRIGHT, 1938).

C. Potássin. Determinado volumètricamente como cobaltinitrito por uma ligeira modificação à técnica de JOHNSON e EPSTEIN (1949).

D. Magnésio. Determinado colorimètricamente pelo amarelo de tiazol por uma modificação à técnica de DROSDOFF e NEARPASS (1948). 


\section{3 - RESULTADOS}

3.1. Ensaios em vasos.

3.1.1. Ensaios com terra da região afetada.

3.1.1.A. Terra sem variação na fator água. No Quadro 6 são dados os resultados culturais e as mediçōes obtidas no ensaio 2.1.1.A.

QUADRO 6

Tratamento

Testemunha

$\mathrm{N}-\mathrm{P}-\mathrm{Ca}$

$\mathrm{N}-\mathrm{P}-\mathrm{K}-\mathrm{Ca}$

$\mathrm{N}-\mathrm{P}-\mathrm{Ca}-\mathrm{Mg}$

$\mathrm{N}-\mathrm{P}-\mathrm{K}-\mathrm{Ca}-\mathrm{Mg}$

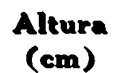

69,1

89,0

84,6

85,5

101,2
Número do
capulhos

7,5

13,0

14,5

16,5

22,0
Fibras

(8)

35,0

55,2

71,2

74,5

100,0

Os dados acima são médias obtidas com 8 plantas (2 plantas por vaso e 4 repetições). No que se refere à análise estatística o teste de $t$ não mostrou diferença significativa entre os tratamentos sem $\mathrm{K}$ e $\mathrm{Mg}$.

E' importante mencionar que não houve nenhuma ocorrência de "vermelhão" como também não apareceu a ferrugem caracterísiica da falta de potássio. Houve, e isso em todos os tratamentos, o aparecimento da cór vermelho-alaranjada que caracteriza o fim do ciclo vegetativo.

3.1.1.B. Terra com variação no fator água. Nos vasos em que as plantas foram ccnservadas com $25 \%$ do poder de embebição o algodoeiro se desenvolveu mal; foi acentuada a ocorrência do "vermelhão" ncs tratamentos sem adubo, sem $\mathrm{Mg}$ e sem $\mathrm{K}$ e $\mathrm{Mg}$, havendo queda prematura das folhas inferiores; no tratamento sem $K$ apareceu a colcração ferruginosa já descrita caminhando da periferia para o centro. Com $50 \%$ do poder de embebição já o desenvolvimento das plantas foi melhor e os sitomas de carência de $\mathrm{K}$ e $\mathrm{Mg}$ se repetiram, mas com muito pouca intensidacle. Com $75 \%$ do poder de embebição não ocorreu nenhum sinal de deficiência.

3.1.1.C. Ensaio em areia lavada. No presente ensaio constatou-se concordância perfeita entre os sintomas de "vermelhäo" que surgiram ncs tratamentos sem e com pouco $\mathrm{Mg}$ e o descri- 
to na literatura já citada em 1.3. Foram tiradas fotografias coloridas e o material foi desenhado a côres. Por outro lado nos tratamentos sem e com pouco $\mathrm{K}$ apareceu a característica "cotton rust", ocorrência que também ficou fixada por fotografias e desenhos coloridos. Deve-se dizer que a incidência tanto do "vermelhão" como da "cotton rust" foi menos acentuada nos tratamentos em que se forneceu, respectivamente, pouco $\mathrm{Mg}$ ou pouco $\mathrm{K}$.

\subsection{Ensaio de campo}

\section{QUADRO 7}

Resultados

\begin{tabular}{|c|c|c|c|c|c|}
\hline Tratamento & Bloco A & Bloco B & Bloco C & Bloco D & Total \\
\hline \multicolumn{6}{|c|}{ Texas (I. A. 7387-24949) } \\
\hline $\begin{array}{l}1 \\
2 \\
3 \\
4\end{array}$ & $\begin{array}{l}3,155 \\
3,460 \\
4,180 \\
4,005\end{array}$ & $\begin{array}{l}3,215 \\
3,325 \\
4,005 \\
4,090\end{array}$ & $\begin{array}{l}3,200 \\
3,390 \\
3,955 \\
3,980\end{array}$ & $\begin{array}{l}3,195 \\
3,400 \\
3,905 \\
4,110\end{array}$ & $\begin{array}{l}12,765 \\
13,575 \\
16,250 \\
15,980\end{array}$ \\
\hline \multicolumn{6}{|c|}{ Express (I. A. 7111-028-16.284) } \\
\hline $\begin{array}{l}1 \\
2 \\
3 \\
4\end{array}$ & $\begin{array}{l}2,670 \\
3,025 \\
3,615 \\
3,440\end{array}$ & $\begin{array}{l}2,610 \\
3,000 \\
3,210 \\
3,015\end{array}$ & $\begin{array}{l}2,595 \\
2,809 \\
3,345 \\
3,355\end{array}$ & $\begin{array}{l}2,485 \\
2,960 \\
3,435 \\
3,535\end{array}$ & $\begin{array}{l}10,360 \\
11,785 \\
13,605 \\
13,345\end{array}$ \\
\hline \multicolumn{6}{|c|}{ I. A. 817 (Campinas - I. Agr. E. S. Paulo) } \\
\hline $\begin{array}{l}1 \\
2 \\
3 \\
4\end{array}$ & $\begin{array}{l}1,905 \\
1,960 \\
2,305 \\
2,270\end{array}$ & $\begin{array}{l}2,005 \\
2,130 \\
2,220 \\
2,280\end{array}$ & $\begin{array}{l}2,125 \\
2,24: 1 \\
2,30 ; \\
2,10\end{array}$ & $\begin{array}{l}2,120 \\
2,270 \\
2,295 \\
2,455\end{array}$ & $\begin{array}{l}8,155 \\
8,600 \\
9,200 \\
9,110\end{array}$ \\
\hline
\end{tabular}

Obs. : A variedade I. A. 817 teve baixa produção, menor que as outras duas variedades, devido à maior ocorrência de vermelhão.

A análise estatística dos dados se acha resumida nos Quadros 8,9 e 10. Nos três casos estudados o valor $F$ mostra que houve diferença significativa entre os tratamentos. Fazendo um teste $t$ para as médias achamos que: as maiores produções foram obtidas quando se usou o potássio combinado ao magnésio; as colheitas conseguidas em ausência de potássio foram menores do que aquelas obtidas sem adicionar magnésio; em vista do resultado enunciado em primeiro lugar é licito dizer que, uma vez garantido o nível necessário de potássio só é possível au- 
mentar a produção adicionando-se magnésio; as formas solúvel (sulfato) e pouco solúvel de magnésio (calcário dolomítico) são pràticamente equivalentes nos seus efeitos sôbre as colheitas.

A ocorrência do "vermelhão" durante o ensaio se acha tabelada no Quadro 11. Vê-se que o "vermelhão" ocorreu de modo marcante no tratamento sem magnésio. Por outro lado a variedade mais afetada foi a I. A. 817. Houve no tratamento 1 (sem K) aparecimento de sintomas característicos da falta de potássio.

QUADRO 8

Análise estatística da variedade Texas

\begin{tabular}{|c|c|c|c|c|c|}
\hline $\begin{array}{c}\text { Origem da } \\
\text { variação }\end{array}$ & $\begin{array}{l}\text { Graus de } \\
\text { liberdade }\end{array}$ & $\begin{array}{l}\text { Somas dos } \\
\text { quadrados }\end{array}$ & $\begin{array}{c}\text { Quadradns } \\
\text { médios }\end{array}$ & $\mathbf{F}$ & $\begin{array}{c}\text { Significun- } \\
\text { cis }\end{array}$ \\
\hline $\begin{array}{l}\text { Blocos } \\
\text { Tratamen. } \\
\text { Erro (por } \\
\text { diferença) }\end{array}$ & $\begin{array}{l}3 \\
3\end{array}$ & $\begin{array}{l}0,046 \\
2,295\end{array}$ & $\begin{array}{l}0,015 \\
0,765 \\
0,001 \\
\end{array}$ & $\begin{array}{r}15 \\
765\end{array}$ & $\begin{array}{l}<1 \% \\
<1 \%\end{array}$ \\
\hline Total & 15 & 2,353 & & & \\
\hline
\end{tabular}

QUADRO 9

Análịse estatística da variedade Express

\begin{tabular}{|c|c|c|c|c|c|}
\hline $\begin{array}{c}\text { Origem da } \\
\text { variação }\end{array}$ & $\begin{array}{l}\text { Graus de } \\
\text { liberdade }\end{array}$ & $\begin{array}{l}\text { Somas dos } \\
\text { quadrados }\end{array}$ & $\begin{array}{c}\text { Quadrados } \\
\text { médios }\end{array}$ & $\mathbf{F}$ & $\begin{array}{c}\text { Significâr- } \\
\text { cia } \\
\end{array}$ \\
\hline Blocos & $\begin{array}{l}3 \\
\mathbf{3}\end{array}$ & $\begin{array}{l}0,139 \\
1,727\end{array}$ & $\begin{array}{l}0,0463 \\
0,5756\end{array}$ & $\begin{array}{l}2,85 \\
35,5\end{array}$ & $\begin{array}{l}>50 \% \mathrm{e}<10 \% \\
<1 \%\end{array}$ \\
\hline diferença) & 9 & 0,146 & 0,0162 & & \\
\hline Total & 15 & 2,012 & & & \\
\hline
\end{tabular}

QUADRO 10

Análise estatística da variedade I. A.

817 (Campinas)

\begin{tabular}{lcccccc}
\hline $\begin{array}{c}\text { Origem da } \\
\text { variação }\end{array}$ & $\begin{array}{c}\text { Graus de } \\
\text { liberdade }\end{array}$ & $\begin{array}{c}\text { Somas dos } \\
\text { quadrados }\end{array}$ & $\begin{array}{c}\text { Quadrados } \\
\text { médios }\end{array}$ & F & $\begin{array}{c}\text { Significn̂n. } \\
\text { cia }\end{array}$ \\
\hline $\begin{array}{c}\text { Blocos } \\
\text { Tratamen. }\end{array}$ & 3 & 0,087 & 0,029 & 3,62 & $>5 \%$ \\
$\begin{array}{c}\text { Erro (por } \\
\text { diferença) }\end{array}$ & 9 & 0,197 & 0,065 & 3,2 & $<1 \%$ \\
\hline Total & 15 & 0,072 & 0,072 & & \\
\hline
\end{tabular}




\section{QUADRO 11}

Ocorrência do "vermelhão"

\begin{tabular}{|c|c|c|}
\hline Variedade & Tratamento & $\begin{array}{l}\text { Plantas com } \\
\text { vermelhão }\end{array}$ \\
\hline $\begin{array}{l}\text { Texas } \\
\text { Texas } \\
\text { Texas } \\
\text { Texas }\end{array}$ & $\begin{array}{l}1 \text { - NPCaMg sem } \mathrm{K} \\
2 \text { 二 NPKCa sem Mg } \\
3 \text { - NPKCaMg (MgSO4) } \\
4 \text { - NPKCaMg (Dolomita) }\end{array}$ & $\begin{array}{r}32 \\
140 \\
8 \\
6\end{array}$ \\
\hline- & 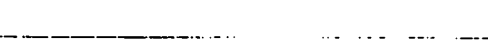 & 186 \\
\hline $\begin{array}{l}\text { Express } \\
\text { Express } \\
\text { Express } \\
\text { Express }\end{array}$ & $\begin{array}{l}\text { 1- } \mathrm{NPCaMg} \text { sem K } \\
2 \text { 二 NPKCa sem Mg } \\
3 \text { - NPKCaMg (MgSO4) } \\
\text { 4- NPKCaMg (Dolomita) }\end{array}$ & $\begin{array}{r}28 \\
142 \\
7 \\
16\end{array}$ \\
\hline & $\cdots$ & 195 \\
\hline \multirow[t]{2}{*}{$\begin{array}{l}\text { I. A. } 817 \\
\text { I. A. } 817 \\
\text { I. A. } 817 \\
\text { I. A. } 817\end{array}$} & $\begin{array}{l}1 \text { - NPCaMg sem } \mathrm{K} \\
2 \text { 二 NPKCa sem Mg } \\
3 \text { 二 NPKCaMg (MgSO4) } \\
\text { 4- NPKCaMg (Dolomita) }\end{array}$ & $\begin{array}{r}26 \\
169 \\
9 \\
12\end{array}$ \\
\hline & & 216 \\
\hline
\end{tabular}

3.3. Análises químicas.

3.3.1. Material colhido nas culturas visitadas. Os resultados se acham no Quadro 12 :

QUADRO 12

\begin{tabular}{|c|c|c|c|c|}
\hline \multirow[t]{2}{*}{ Limbos } & \multicolumn{2}{|c|}{$\mathrm{Mg} 0 \%$} & \multicolumn{2}{|c|}{ K2 0\% } \\
\hline & & Iat. verde & Cinzas & Mat. ver de \\
\hline Verde & 22,4 & 2,5 & 17,8 & 2,0 \\
\hline Pintado & 18,4 & 1,9 & 17,0 & 1,8 \\
\hline verde-vermelho & 17,3 & 1,7 & 13,7 & 1,1 \\
\hline Vermelho & 16,4 & 1,3 & 11,1 & 1,0 \\
\hline \multicolumn{5}{|l|}{ Peciolo } \\
\hline Verde & 20,7 & 2,2 & 27,5 & 2,9 \\
\hline Pintado & 17,0 & 1,6 & 27,3 & 2,5 \\
\hline verde-vermelho & 16,3 & 1,4 & 22,6 & 2,1 \\
\hline Vermelho & 14,6 & 1,2 & 19,3 & 1,6 \\
\hline
\end{tabular}

3.3.2. Material colhido no ensaio de vasos (terra) com variação no fator água. Os resultados aparecem no Quadro 13. 
QUADRO 13

$\mathrm{K} 2 \mathrm{O}$ e $\mathrm{MgO}$ nas cinzas das folhas (limbo + pecíolo)

\begin{tabular}{|c|c|c|}
\hline Tratamento & K20\% & Mg0\% \\
\hline $\begin{array}{l}\text { Testemunha }+25 \% \text { p. embeb. } \\
\text { Testemunha }+50 \% \text { p. embeb. } \\
\text { Testemunha }+75 \% \text { p. embeb. } \\
\text { N-P - Ca }+25 \% \text { p. embeb. } \\
\text { N-P - Ca }+50 \% \text { p. embeb. } \\
\text { N-P - Ca }+75 \% \text { p embeb. } \\
\text { N-P }-\mathrm{K}-\mathrm{Ca}+25 \% \text { p. embeb. } \\
\mathrm{N}-\mathrm{P}-\mathrm{K}-\mathrm{Ca}+50 \% \text { p. embeb. } \\
\mathrm{N}-\mathrm{P}-\mathrm{K}-\mathrm{Ca}+75 \% \text { p. embeb. } \\
\mathrm{N}-\mathrm{P}-\mathrm{Ca}-\mathrm{Mg}+25 \% \text { p. embeb. } \\
\mathrm{N}-\mathrm{P}-\mathrm{Ca}-\mathrm{Mg}+50 \% \text { p. embeb. } \\
\mathrm{N}-\mathrm{P}-\mathrm{Ca}-\mathrm{Mg}+75 \% \text { p. embeb. } \\
\mathrm{N}-\mathrm{P}-\mathrm{K}-\mathrm{Ca}-\mathrm{Mg}+25 \% \text { p. embeb. } \\
\mathrm{N}-\mathrm{P}-\mathrm{K}-\mathrm{Ca}-\mathrm{Mg}+50 \% \text { p. embeb. } \\
\mathrm{N}-\mathrm{P}-\mathrm{K}-\mathrm{Ca}-\mathrm{Mg}+75 \% \text { p. embeb. }\end{array}$ & $\begin{array}{r}15,5 \\
13,6 \\
13,4 \\
4,1 \\
4,5 \\
4,2 \\
13,4 \\
13,6 \\
15,1 \\
3,8 \\
3,4 \\
3,3 \\
14,2 \\
14,8 \\
13.4\end{array}$ & $\begin{array}{r}8,0 \\
10,4 \\
11,6 \\
10,2 \\
12,6 \\
12,6 \\
10,2 \\
10,0 \\
9,5 \\
9,5 \\
10,9 \\
10,1 \\
8,7 \\
10,4 \\
9,4 \\
10,0\end{array}$ \\
\hline
\end{tabular}

Para obter os dados acima, o material de cada vaso foi analisado separadamente; a seguir tirou-se a média das três repetições.

3.3.3. Material colhido no ensaio de campo. Os dados se encontram no Quadro 14.

QUADRO 14

Parte da planta

\begin{tabular}{lcccc}
\hline \multicolumn{1}{c}{ Material } & \multicolumn{2}{c}{ Limbo } & \multicolumn{2}{c}{ Pecíolo } \\
& K2 0\% & Mg 0\% & K2 0\% & Mg 0\% \\
\hline Texas-verde & 1,14 & 2,14 & 1,43 & 3,12 \\
Texas-carência de K & 0,66 & 2,26 & 0,44 & 2,41 \\
Express-verde & 1,13 & 1,78 & 1,94 & 3,16 \\
Express-carência de K & 0,51 & 2,73 & 0,67 & 2,89 \\
I. A. 817 - verde & 1,00 & 1,69 & 1,93 & 3,46 \\
I. A. 817 - carência de K & 0,63 & 1,74 & 0,64 & 3,64 \\
\hline
\end{tabular}

\section{4 - DISCUSSÃO}

4.1. Ensaios $\mathrm{cm}$ vasos.

4.1.1. Enscios coin terra da região afetada.

4.1.1.A. Terra sem variação no fator água. Os resultados que constam do Quadro 6 (em 3.1.1.A.) mcstram que as diferenças entre os tratr mentos sem $\mathrm{K}$ e sem $\mathrm{Mg}$ no que se refere à altura 
das plantas, número de capulhos e pêso de fibras são desprezíveis. Por outro lado verifica-se que os tratamentos citados se afastam bastante da adubação completa. Segue-se daí que, provàvelmente, $\mathrm{K}$ e $\mathrm{Mg}$ se achavam limitantes nas condições do ensaio. Os dados que temos não nos permitem, entretanto, esclarecer qual desses dois catiônios esiava no mínimo. O que é importante para o presente trabalho é o fato de que, mesmo não se fornecendo $\mathrm{K}$ e $\mathrm{Mg}$ na adubacão os sintomas de ferrugem e "vermelhão" não apareceram. Vê-se logo que o simples fornecimento duma quantidade adequada de água foi bastante para evitar a manifestação dos sintomas de carência. Este ponto ficou mais claro em face dos resultados do ensaio com terra em que se fez variar o fator água. E' necessário salieniar que a água por si só foi capaz de mobilizar uma quantidade de $\mathrm{K}$ e $\mathrm{Mg}$ tal que, embora o crescimento e a produção permanecessem limitados, a sintomatologia típica não cheğou a aparecer.

4.1.1.B. Terra com variação no fator água. Os resultados do presente experimento, como se viu em 3.1.1.B., provaram amplamente a hipótese levantada em 4.1.1.A. Trouxeram ainda um apoio, si bem que parcial a ABRAHÃO et al. (1952) (ver 1.3.); dizemos parcial uma vez que a verdadeira causa do "vermelhão" é a diminuição severa na assimilação do $\mathrm{Mg}$ e não do $\mathrm{K}$ como pretendiam aqueles autores. Com níveis baixos de umidade no solo - 25 e mesmo $50 \%$ do poder de embebição - a quantidade de $\mathrm{K}$ e $\mathrm{Mg}$ mobilizadas do complexo coloidal não são suficientes para atender à necessidade do algodoeiro. Como se sabe (ver PEECH, 1948) o potássio e também o magnésio (PRINCE et al., 1947) ocorrem nos solos de maneira a manter as seguintes relações de equilíbrio:

$\mathrm{K}$ não trocável $\longrightarrow \mathrm{K}$ trocável $\longrightarrow \mathrm{K}$ na solução do solo

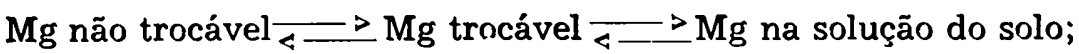

de acôrdo com os trabalhos de JENNY e colaboradores (ver JENNY, 1951) os vegetais superiores seriam capazes de, por dupla troca, se aproveitar dos cationnios adsorvidos ao complexo coloidal desde que as esferas de oscilação destes se confundissem com aquelas dos iônios de hidrogênio dos pelos absorventes. No caso do algodoeiro, aparentemente tal não se dá; o efeito da água seria o de deslocar o equilbrío para a direita de modo a por mais $\mathrm{K}$ e mais $\mathrm{Mg}$ à disposição da planta. Achamos esta explicação mais aceitável : a possibilidade da passagem do $\mathrm{K}$ e do Mg para a forma não trocável nas condições de sêca 
(VOLK, 1934) no solo em estudo não deve ocorrer uma vez que se trata de solos com caolinita.

Em ligação com os resultados por nós obtidos no que se refere à nítida resposta a $\mathrm{Mg}$, os dados que apresentamos não concordam com a conclusão de PRINCE et al. (1947): para eles desde que o $\mathrm{Mg}$ trocável do solo representasse 10 por cento de $S$ (base toiais) não haveria necessidade de adubação magnesiana; como se pode ver em 2.1.1.A. no solo estudado o teor de $\mathrm{Mg}-\mathrm{L}+$ corrcsponde a 15 por cento de $\mathrm{S}$.

4.1.2. Ensaio em areia lavada. Este ensaio foi conduzido com a finalidade precípua de verificar si a omissão do $\mathrm{Mg}$ da solução nutritiva provocaria os sintomas do "vermelhão". Por outro lado pretendiamos verificar de perto as diferenças entre os sintomas de carência de potássio - "cotton rust" dos americanos - e os de falta de magnnésio. Foi verificado então que na falta ou insuficiência de $\mathrm{Mg}$ na solução nutritiva as fôlhas das plantas correspondentes mostram no inicio a clorose usual; os sintomas começam a se manifestar nas folhas mais velhas; a clorose se acentúa e começam a parecer manchas avermelhadas distribuidas irregularmente na lâmina foliar; depois, aos poucos a côr vermelha se acentúa, adquire tons de púrpura e toma conta de tôdos os espaços internervais; as nervuras, tanto as principais como as suas ramificações permanecem verdes; com o progredir das condições de carência, as fôlhas secam e dá-se a abcisão, fenômeno mais ou menos simultâneo com a abertura das maçãs.

No caso dos tratamentos sem e com pouco potássio a marcha dos sintomas foi mais ou menos paralela à verificada com 0 magnésio; isto sugere uma semelhança entre a dinâmica desses dois elementos no algodoeiro. Aqui também os sinais de carência de potássio concordaram muito bem com aqueles da literatura. Apareceu, a princípio, uma coloração ferruginosa na periferia do limbo, a qual, aos poucos tomou conta de tôdas as fôlhas; estas nos últimos estágios se tornaram quebradiças, caindo. COWIE (1951) descreve assim os sintomas de carências de $\mathrm{K}$ no algcdoeiro: "Potassium has been found more useful in dry regions and especially for the prevention of rust. This is a malnutritional symptom commonly called "potash hunger" or "cotton rust". The first symptom on the leaf is a yellowish-white mottling. The leaf assumes a light yellowish green and yellow spots appzar beiween the veins. In these spots the tissue dies with the result that brown specks occur at the tip, around the tip, around the margin and between the veins. The tip and the margin of the leaf break down first and curl downwards. Fi- 
nally the whole leaf becomes reddish brown in colour, dries up and falls off prematurely". (O grifo é nosso).

Em todos os tratamentos registrou-se, no fim do ciclo de vida das plantas, o aparecimento duma coloração vermelho-alaranjada nas fôlhas; tal coloração, era bem distinta das manifestaçōes de carência citadas.

\subsection{Ensaio de campo.}

De acôrdo com o Quadro 7 e a análise estatística verificase que foi benéfica a influência do $\mathrm{Mg}$ em todos os casos quer se considere o sulfato ou a dolomita. Entretanto, as colheitas obtidas em ausência de potássio foram um pouco menores do que as obtidas em ausência de magnésio; explicação para isto já foi sugerida em outro lugar (ver 3.2.). A eficiência da forma pouco solúvel de $\mathrm{Mg}$ (dolomita) foi comparável à do sulfato; neste ponto os nossos resultados concordam com os de COOPER e WALLACE (1937). Contudo o efeito depressivo na colheita consequente à adição de $\mathrm{Mg}$ em ausência de $\mathrm{K}$ não ocorreu no nosso ensaio. $O$ fato de que uma forma barata de magnésio, qual seja a dolomita, tenha dado bons resultados, não só na elevação da colheita, como no contrôle do "vermelhão" (ver Quadro11) recomenda a inclusão desse material nas fórmulas usualmente empregadas na adubação do algodoeiro; a dose a empregar estaria ao redor de 500-600 quilos de dolomita por hectare.

O Quadro 11 mostra como ocorreu, nos diversos tratamentos, o "vermelhão"; verifica-se por esse quadro que a moléstia é controlada pela adição do $\mathrm{Mg}$, o potássio não tendo influência alguma no aparecimento dos sintomas; vê-se, também, que das três variedades comparadas, a I. A. 817 é a mais sucetive] ao "vermelhão" nas condições do ensaio.

\subsection{Análises químicas.}

\subsubsection{Material de uma cultura visitada.}

Os dados do Quadro 12 mostram que nas condições naturais de cultura no campo (Fazenda "Vai e vem", município de Piracicaba) há uma queda porcentual - nas fôlhas com "vermelhão" em diversas fases - tanto no teor de potássio como no de magnésio. Embora houvesse também queda na quantidade de $K$, as fôlhas não revelaram os sintomas de carência de $K$, mas apenas os de $\mathrm{Mg}$. Ainda : a diminuição no teor de $\mathrm{K}$ foi sempre igual ou ligeiramente maior que aquela do $\mathrm{Mg}$. Do que ficou escrito deduz-se que: a diminuição notada no conteúdo de $\mathrm{Mg}$ representa muito mais para a fisiologia do algodoeiro 
que a queda na quantidade de potássio; outra explicação seria : os sintomas da carência de $\mathrm{Mg}$ mascararam completamente os da falta de $\mathrm{K}$, o que, aliás, não é fato inédito em fisiologia. Voltaremos a este assunto mais adiante.

O Quadro 12 fornece uma demonstração clara da mobilidade do $\mathrm{K}$ e do $\mathrm{Mg}$ no algodoeiro. A este respeito, WALLACE (1944) escreve : "The element $(\mathrm{Mg})$ seems to be very mobile within the plani, and when deficient is apparently transferred from older to younger tissues where it can be re-utilised in the growth processes. This agrees with the observation that signs of magnesium deficiency invariably make their appearance first on the oldest leaves and progress systematically from the towards to the youngest ones".

Achamos oportuno discutir agora a opinião de SAUER (1950) citada no segundo parágrafo de 1.3. Em vista dos nossos dados sôbre a ocorrência do "vermelhão" e a redistribuição do Mg na planta discordamos daquele autor julgando que o fenômeno de impedimento parcial da translocação dos produtos de assimilação para o caule e para as fôlhas é uma consequência a não uma causa do "vermelhäo". De fato, segundo RAUMER (1883) - cuja opiniäo foi corroborada posteriormente por muitos outros investigadores - o $\mathrm{Mg}$ está implicado na translocação dos carbohidratos. Sendo assim, é razoável admitir que os carbohidratos concentrados nas fôlhas como consequência da falta de Mg representassem uma, digamos, atração, para os insetos sugadores.

\subsubsection{Material do ensaio em vasos com terra variando o fator água.}

Examinando o Quadro 13 (ver 3.3.2.) verifica-se que os dados näo são suficientes para estabelecer uma correlação satisfatória - num tratamento dado - entre nível de umidade e teor de $\mathrm{K}$ ou $\mathrm{Mg}$ na planta. Por outro lado as diferenças entre tratamentos, complicam o aspecto não permitindo comparações entre os vários grupos de plantas tomando por base o fator água. Entretanto, algumas consequências são evidentes: a ausência do elemento $K$ na adubação sempre reduziu fortemente o teor do mesmo nas fôlhas; verifica-se também que no solo em estudo a omissão do potássio na mistura de adubos ocasionou uma queda considerável no teor desse elemento: de $14 \%$ em $\mathrm{N}-\mathrm{P}-\mathrm{K}-\mathrm{Ca}-\mathrm{Mg}$ até $4 \%$ em N-P-Ca e 3,5\% em N-P-Ca-Mg; por outro lado, a adição de $\mathrm{Mg}$ na adubação provou ligeira diminuição no teor de $\mathrm{K}$. A incorporação de $\mathrm{Mg}$ embora tivesse - como já vimos - influido bastante na incidência do "vermelhão", 
aparentemente não alterou apreciàvelmente a quantidade total de $\mathrm{Mg}$ na folha. Si houve ou não influência em formas particularmente "ativas" de Mg na planta é especulativo.

4.3.2. - Material do ensaio de campo. Os dados do Quadro 14 em que só se analisou plantas com sintomas de carências de $\mathrm{K}$ mostram que: houve uma redução drástica no teor desse elemento nas plantas deficientes; os pecíolos mostram melhor do que o limbo foliar o estado da planta no que se refere ao seu estado de potássio. Daremos a seguir resultados de análises feitas com material de plantas cultivadas em solução nutritiva do Eng. Agr. Heli Camargo Mendes, da Secção de Fisiologia Vegetal do Inst. Agr. do E. S. Paulo, Campinas) :

\section{QUADRO 15}

\section{Tratamentos}

Plantas normais, que vegetaram em sol. nutr. completa de $30-9$ a 3-4-50

Plantas carentes em $K$, que vegetaram em sol. completa entre 30-9 e 19-11; de 19-11 até 3-4-50 em sol. sem $K$

\begin{abstract}
K20\% na mat. sêca
Fôlhas Ramos Brácteas
\end{abstract}

$\begin{array}{lll}4,68 & 1,46 & 7.82 \\ 0,91 & 0.25 & 1.97\end{array}$

Em 4.3.1. levantamos a hipótese de que a carência de $\mathrm{Mg}$ ("vermelhão") no caso da cultura visitada tivesse mascarado uma possível deficiência simultânea de K. Agora : a comparação dos dados do Quadro 14 com os do Quadro 15 mostra logo que o material com que trabalhamos era de fato deficiente de $\mathrm{K}$, uma vez que a proporção desse elemento no nosso material desceu e um valor ainda menor do que os obtidos por nosss colega H. C. Mendes. Por outro lado, o Quadro 12 mostra logo que nas fôlhas com "vermelhão" o teor de $\mathrm{K}$ permaneceu sempre acima do limite que aparece no Quadro 15 . A nosso ver isto afasta a hipótese levantada por nós; consequentemente o Quadro 12 indica carência de $\mathrm{Mg}$ apenas.

\section{5 - RESUMO E CONCLUSÕES}

Durante os anos de 1948, 1949 e 1951 ocorreu nas culturas de algodoeiro do estado de São Paulo uma doença que acarretou considerável queda na produção das regiōes afetadas. A anomalia se caracterizava por um avermelhamento típico das fôlhas e daí tirou o nome. 
Entre as causas fisiológicas apontadas como responsável estavam : carência de potássio - de onde surgiu uma outra denominação, "fome de potássio" - e carência de magnésio.

Para estudar o problema, a Secção de Química Agrícola conduziu a seguinte série de experimentos:

1. em vasos, com solo (terra roxa) de uma das regiōes afetadas;

2. em vasos, com solo e diferentes níveis de umidade;

3. em vases, com areia lavada, omitindo-se determinados elementos;

4. ensaios de campo, em terra arenosa, com as variedades Texas, Express e I. A. 817; forneceu-se $\mathrm{K}$ e Mg, este como sulfato e como dolomita.

Todos os ensaios foram completados com a análise química das fôlhas das plantas.

Os resultados se resumem assim :

1. no caso do primeiro ensaio, nos vasos não adubados convenientemente, se reproduziram os sintomas verificados nas culturas visitadas; foi possível distinguir três diferentes tipos de avermelhamento : em ausência de $\mathrm{K}$, surgiu uma coloração ferruginosa nos bordos das fôlhas; em ausência de $\mathrm{Mg}$, houve o aparecimento de uma coloração vermelho púrpura idêntica d̀ encontrada na maioria das culturas examinadas; há ainda que citar a coloração vermelho-laranja peculiar às fôlhas do algodoeiro no fim do ciclo;

2. no segundo ensaio constatou-se que quando os vasos eram mantidos com 75 ou 100 por cento do poder de embebição não havia o desenvolvimento dos dois primeiros tipos de avermelhamento mesmo quando o solo não recebera adubação alguma; mantendo-se apenas 25 por cento do poder de embebição apareceram os sintomas mencionados;

3. o ensaio em areia lavada confirmou os agentes causais da sintomatologia descrita;

4. no experimento de campo, a variedade I.A. 817 foi a mais afetada pelo "vermelhão"; nos canteiros sem K apareceram sintomas típicos da carência desse elemento; tanto a dolomita como o sulfato de magnésio evitaram perfeitamente $o$ aparecimento do "vermelhão";

5. analisando-se o material colhido no campo e em vasos verificou-se que o pecíolo é a parte da fôlha que indica melhor o estado da planta com respeito ao $\mathrm{K}$ e ao $\mathrm{Mg}$; no material mostrando diversos gráus de "vermelhão" a flutuação no nível de $\mathrm{Mg}$ é muito maior que a variação do teor de $\mathrm{K}$; o contrário se dá quando há o sintoma de carência de $\mathrm{K}$. 
Em vista do que ficou acima pode-se concluir que :

1. o $\mathrm{Mg}$ é o agente causal do "vermelhão" do algodoeiro;

2. houve também nas regiões afetadas carência de $K$ mas em gráu menos acentuado;

3. as condições climáticas - especialmente a falta de chuvas influiram na dinâmica do $\mathrm{K}$ e especialmente do $\mathrm{Mg}$ reduzindo-lhes drásticamente a assimilação.

\section{6 - SUMMARY}

During the years 1948, 1949 and 1951 a disease occurred in the cotton crops of the state of S. Paulo Brazil (S. Am.), which caused a severe drop in yields. The abnormality was characterized by a typical reddish - purple color of the leaves, being by this reason, called "vermelhão", that is, reddening of the cotton plant. The disease was associated with a dry season.

Among the several hypotheses raised to explain the causes of the disease were: insect attack, potassium deficiency where from the name "potash hunger" was also given -, and magnesium deficiency :

In order to study the problem the Department of Agricultural Chemistry of the College of Agriculture of the University of São Paulo, at Piracicaba, carried out a series of experiments as follows :

1. pot experiments in which soil of one of the affected regions was used ("terra roxa", a red-brownish soil derived from basalt);

2. pot-soil experiments varying the moisture supplied;

3. sand culture experiments omitting certain elements from the nutrient solutions;

4. field plot experiments, conducted on a sandy soil; three different varieties were employed: Texas, Express, and I.A. 817; magnesium was applied either as sulfate or dolomitic limestone.

All the experiments were completed with suitable chemical analyses.

The results can be summarized as follows:

1 . in the first trial, the not properly manured pots (minus $\mathrm{Mg}$ ), symptoms were registered which were similar to the symptoms observed in the field; it was possible to establish some differences among three different types of reddening : due to lack of $\mathrm{K}$ in the mixed fertilizers used, the characteristic cotton rust made its appearance, the red color in the leaves of the minus $\mathrm{Mg}$ plants was all alike that described in the current literature as a symptom of Mg-deficiency; in all the treatments 
ocurred a yellow-reddish colcr in the leaves associated with the latest stages of maturity;

2. in the second experiment it was verified that when the plants in the pots with soil were kept 75 per cent of the water holding capacity, no sympiom of deficiency showed up; was true even for the plants not receiving neither $\mathrm{K}$ nor $\mathrm{Mg}$; however, plants supplied with only 25 per cent of the water holding capacity showed, respectively, cotton rust in the minus $\mathrm{K}$ treatment and the red purplish color in the minus Mg series;

3. the sand culture experiment confirmed lack of $\mathrm{Mg}$ as the cause of "vermelhão", being potash deficiency the responsible for cotton rust;

4. in the field experiment, variety I.A. 817 revealed to be the most sensitive to "vermelhäo" when Mg was omitted from the fertilizers; symptoms of $K$ deficiency appeared when no $K$ was supplied; both magnesium sulfate and dolomitic limestone proved to be equally effective in the control of "vermelhão";

5. the analyses of material collected both in the field as well in the pots revealed that leaf petiole in the most reliable part to indicate the $\mathrm{K}$ and $\mathrm{Mg}$ status of the plant; the variation in $\mathrm{Mg}$ content suffered by the plants showing different stages of "vermelhão was, quantitatively, at least as large as that in $\mathrm{K}$ content, however when one deals with $\mathrm{K}$ deficient plants, that is, plants showing the typical rust, no variation occurred in the $\mathrm{Mg}$ content, whereas $\mathrm{K}$ in the dry mater dropped from more than 1 per cent to less than half per cent.

Then, the following general conclusions can be drawn:

1. Mg deficiency is the cause of "vermelhäo" of cotton crops;

2. $\mathrm{K}$ deficiency also occurred, but in a lesser degree;

3. the climate conditions - especially the lack of rain influenced the soil dynamic of $\mathrm{K}$, and especially $\mathrm{Mg}$, bringing a severe reduction in their assimilability;

4. the "vermelhão" disease can be easily controlled upon additions either of magnesium sulfate or dolomitic limestone.

\section{7 - LITERATURA CITADA}

ABRAHAO, J., A. C. ANDRADE e A. A. BITANCOURT. 1952 O "vermelhão" ou "fome de potássio" do algodoeiro, um desequilíbrio fisiológico entre a folhagem e a frutificação. 2a. Reuniäo Sulamericana de Fitogeneticistas e Fitoparasitologistas (Piracicaba, Abril). Mimeogr. 
A. O. A. C. $1948 \mathrm{Em}$ "Official and tentative methods of analy sis", sixth edit. publ. by the Assoc. Offic. Agric. Chem., Washington, D. C.

ARNON, D. I. and D. R. HOAGLAND. 1943 Composition of the tomato plant as influenced by nutrient supply, in relation to fruiting. Bot. Gaz. 104: 576-590.

AVERNA-SACCA, R. 1912 Chlorosis of orange and other plants on ferruginous soils. Bol. Agr. (S. Paulo), 13, ser. 1912, n. 2: 129-150. (B.L.M.E., vol. 1, p. 1076, 1948).

BARNES, W. C. 1943 Effect of soil acidity and some minor elements on the growth of Irish potatoes. S. C. Agr. Expt. Sta. Ann. Retp.: 127-132.

BEMELMANS, J. 1952 A fome de potássio. Bol. Sup. Serv. Tec. Café 304: 500-504.

CIFERRI, R. Sem data Em "Fisiologia Vegetale", Edizione Agricole - Bologna.

COOIL, B. J. 1948 Potassium deficiency and excess in guayule. II. Cation-anion balance in the leaves. Plant Physiol. 23: 403-424.

COOIL, B. J. and M. C. SLATTERY. 1948 Effects of potassium deficiency and excess upon certain carbohydrate ond nitrogenous constituents in guayule. Plant Physiol. 22: 425-442.

COOPER, H. P. and R. W. WALLACE. 1937 Results from an experiment upon the use with cotton of various sources of potash salts with and without lime and magnesium. S. Carolina Agr. Expt. Sta. 50th Ann. Rept.: 129-130.

COOPER, H. P., W. B. ROGERS and R. W. WALLACE. 1943 Experiments with potash fertilizer for cotton. S. Carolina Agr. Expt. Sta. 47th Ann. Rept.: 16-18.

COWIE, G. A. 1951 Em "Potash", Edward Arnold and Co., London.

DIXON, M. 1949 Em "Multienzyme Systems", Cambridge Univ. Press, Cambridge.

DROSDOFF, M. and D. C. NEARPASS. 1948 Quantitative microdetermination of magnesium in plant tissue and soil extracts. Anal. Chem. 20: 673-674.

ECKSTEIN, O., A. BRUNO, J. W. TURRENTINE. $1937 \quad E m$ "Kenzeichen des Kalimangels", Verlagsgesellschaft fur Ackerbau, Berlin.

HACKEMANN, F. 1952 Fome de potássio. Sind. Ind Ad. Colas Est. S. Paulo Circ. 58-52.

HEWITT, E. J. 1951 The role of the mineral elements in plant nutrition. Ann. Rev. Plant Physiol. 2: 25-52. 
HOAGLAND, D. R. and D. I. ARNON. 1950 The water culture method for growing plants without soil. Calif. Agr. Expt. Sta. Circ. 347.

JAVILLIER, M. et S. GOUDSCHAUX. 1940 The magnesium of chlorophyll. Ann. Agron. 10: 9-14.

JENNY, H. 1951 Em "Mineral nutrition of plants", ed. E. Troug, The University of Wisconsin Press.

JOHNSON, C. M. and E. EPSTEIN. $1949 \mathrm{Em}$ "Methods of chemical analysis. Soil Science 113 University of California". Mimeogr.

JONES, E. W. and E. J. HEWITT. 1950 Cit. em MALAVOLTA, 1953.

LEHR, J. J. 1949-50 Exploratory pot experiments on sensitiveness of different crops to sodium : A. Spinach. Plant and Soil 2: 37-48.

LOEW, O. 1903 The physiological role of mineral nutrients in plants. U. S. D. A. Bur. Plant Ind. Bul. 45.

MALAVOLTA, E. 1953 Em "Apontamentos de Química Agrícola. II. Química Vegetal", Piracicaba, Mimeogr.

MAMELI, E. 1912 Sulla influenza del magnesio sopra la formazione della chlcrefilla. Inst. Bot. Univ. Pavia (Ser. 2) 15: 151-205.

MC MURTREY, J. E. $1948 \mathrm{Em}$ "Diagnostic techniques for soils and crops", publ. by the American Potash Institute, Washington, D. C.

MITSCHERLICH, E. A. $1930 \mathrm{Em}$ "Die Bestimmung des Dungerbedurfnisses des Bodens", 3a. ed., Paul Parey, Berlin.

MULDER, E. G. 1949 Invesiigations on the nitrogen nutrition of agricultural crops. I. Experiments with ammonium nitrate limestcne cn grassiand. Verlag. Landbouwk. Onderzoek. N. 55.7: 1-95. (C. A. 44 (3): 5508. 1950).

MULDER, E. G. 1950 Mineral nutrition of plants. Ann. Rev. Plant Physiol. 1: 1-24.

MULLISON, W. R. and E. MULLISON. 1942 Growth responses of barley secdlings in relation to $\mathrm{K}$ and $\mathrm{Na}$ nutrition. Plant. Physiol. 17: 632-644.

OLSEN, C. 1948-a Absorptively bound potassium in beech leaf cells. Physiol. Plantarum 1: 136-141.

OLSEN, C. 1948-b The mineral, nitrogen, and sugar contens of beech leaves and beech-leaf sap at various times. Compt. rend. trav. lab. Carlsb. sér. chim. 26: 197-230. 
PAIVA NETTO, J. DE, R. A. CATANI, M. S. QUEIROZ e A KUPPER. $1950 \mathrm{Em}$ "Anais da Primeira Reunião Brasileira de Ciência do Solo", publ. pela Scc. Bras. de Ciência do Solo, Rio de Janeiro.

PEECH, M. 1948 Em "Diagnostic techniques for soils and crops", Publ. by the American Potash Institute, Washington, D. C.

PFEIFFER, T. 1918 Em "Der Vegetatationversuch", Verlagsbuchhandlung Paul Parey, Berlin.

PRINCE, A. L., M. ZIMMERMAN and F. E. BEAR. 1947 The magnesium supplying powers of $20 \mathrm{New}$ Jersey soils. Soil Sci. 63: 69-78.

RABINOWITCH, E. I. $1945 \mathrm{Em}$ "Photosynthesis and related processes", vol. 1, Interscience Publ., Inc., New York.

RAUMER, E. VON. $1883 \mathrm{Kalk}$ und Magnesia in der Pflanze. Landw. Vers. Sta. 19: 253-208.

SAUER, H. $1950 \mathrm{O}$ avermelhamento das fôlhas do algodoeiro seria uma consequência de ataque do pulgão. "Fôlha da Manhã" (S. Paulo) 12 jan. $1950: 11$

STOUT, P. R., R. OVERSTREET, L. JACOBSON and A ULRICH. 1947 The use of radioactive tracers in plant nutrition studies. Soil Sci. Soc. Amer. Proc. 12: 91-97.

TRUOG, E., R. J. GOATES, G. C. GERLOFF and K. C. BERGER. 1947 Magnesium-phosphorus relationships in plant nutrition. Soil Sci. 63: 19-25.

VOLK, N. J. 1934 The fixation of potash in difficultly available forms in soils. Soil Sci. 37: 267-287.

WALLACE, T. $1944 \mathrm{Em}$ "The diagnosis of mineral deficiencies in plants by visual symptoms", His Majesty's Stationery Office, London.

WALLACE, T. and E. J. HEWITT. 1946 Studies in iron deficiency of crops I. Problems of iron deficiency and the interrelationships of mineral elements in iron nutrition. The Jour. Pomol. Hort. Sci. 22: (3-4) : 153-161.

WALSH, T. and E. J. CLARK. 1945 Chlorosis of tomatoes with particular reference to potassium-magnesium relations. Proc. Roy. Irish Acad. 50B: 245-263.

WALSH, T. and T. F. O'DONOHOE. 1945 Magnesium deficiency in some crops plants in relation to the level of potassium nutrition. Jour. Agr. Sci. 35: 254-263.

WILLSTATTER, R. und A. STOLL. $1913 \mathrm{Em}$ "Untersuchungen uber chlorophyll. Methoden und Ergebnisse", Berlin.

ZIMMERMAN, M. 1947 Magnesium in plants. Soil Sci. 63: 1-12. 